\title{
Spatial Variations of Soil Respiration in Arid Ecosystems
}

\author{
Gang Liu1, Rei Sonobe², Quan Wang² \\ ${ }^{1}$ Graduate School of Science and Technology, Shizuoka University, Shizuoka, Japan \\ ${ }^{2}$ Faculty of Agriculture, Shizuoka University, Shizuoka, Japan \\ Email: jerrylg@163.com
}

Received 28 January 2016; accepted 27 March 2016; published 30 March 2016

Copyright (C) 2016 by authors and Scientific Research Publishing Inc.

This work is licensed under the Creative Commons Attribution International License (CC BY). http://creativecommons.org/licenses/by/4.0/

(c) (i) Open Access

\section{Abstract}

Soil respiration releases a major carbon flux back to atmosphere and thus plays an important role in global carbon cycling. Soil respiration is well known for its significant spatial variation in terrestrial ecosystems, especially in fragile ecosystems of arid land, where vegetation is distributed sparsely and the climate changes dramatically. In this study, soil respiration in three typical arid ecosystems: desert ecosystem (DE), desert-farmland transition ecosystem (TE) and farmland ecosystem (FE) in an arid area of northwestern China were studied for their spatial variations in 2012 and 2013. Along with soil respiration (SR), soil surface temperature (ST), soil moisture (SM) and soil electrical conductivity (ECb) were also recorded to investigate the spatial variations and the correlations among them. The results revealed that averaged soil respiration rate was much lower in DE than those in TE and FE. No single factor could adequately explain the variation of soil respiration, except a negative relationship between soil temperature and soil respiration in FE $(P<$ 0.05). Geostatistical analysis showed that the spatial heterogeneity of soil respiration in DE was insignificant but notably in both TE and FE, especially in FE, which was mainly attributed to the different vegetation or soil moisture characteristics in the three ecosystems. The results obtained in this study will help to provide a better understanding on spatial variations of soil respiration and soil properties in arid ecosystems and also on macroscale carbon cycling evaluations.

\section{Keywords}

Soil Respiration, Spatial Variation, Arid Ecosystems, Geostatistics, Temperature, Moisture

\section{Introduction}

Soil respiration is a major contributor to net carbon exchange in terrestrial ecosystems and has been estimated to about $25 \%$ of global $\mathrm{CO}_{2}$ evolution [1], and ranked secondly in magnitude just next to photosynthesis by plants 
[2]. Increasing concerns with global warming and its effects on our future environment require a better understanding and qualification of the global carbon cycling processes [3], in which soil respiration plays a crucial role. Soil respiration in different terrestrial ecosystems, especially in forest ecosystems, has been extensively investigated due to its large organic carbon pools and fluxes. While in arid and semiarid lands, which occupy over $40 \%$ of the earth's total surface [4], relatively less attention has been received compared with other ecosystems [5] [6]. Our knowledge about the variations of soil respiration and its controlling factors in the arid ecosystems is yet relatively limited [7].

The process of soil respiration is affected by various abiotic and biotic factors, which all undergo significant temporal and spatial changes and hence difficult to grasp [8]. Understanding on spatial variation of soil respiration is crucial to estimate representative soil respiration within an ecosystem [9], including those in arid areas, where the distribution of ecological factors and organisms is markedly patchy [10] [11]. As pointed out by [11], spatial variations of soil characteristics are largely controlled by the spatial organization of perennial plants in desert ecosystems, noted as "islands of fertility". In addition to the effects of the patchy distribution of vegetation, heterogeneity of soil properties, such as soil temperature, soil moisture, soil salinity/alkalinity and soil microbial organic carbon, may further complicate the spatial variation of soil respiration [8]. As such, the specific spatial patterns of soil respiration and its relationship with these soil properties in arid ecosystems are still poorly known.

In this study, we try to characterize plot scale spatial variation of soil respiration in three typical arid ecosystems, including sandy soil in the desert ecosystem (DE), silty clay loam in desert-farmland ecotone (or the transition ecosystem TE) and sandy loam in farmland ecosystem (FE). Soil respiration (SR) was estimated using the soda lime method, along with related soil properties such as soil surface temperature (ST), soil moisture (SM) and soil electrical conductivity (ECb) being collected simultaneously. Our main objectives are to estimate and compare the magnitudes of soil respiration in different arid ecosystems and to figure out their controlling factors and also to illustrate their spatial variations by using geostatistic analysis.

\section{Materials and Methods}

\subsection{Study Area}

The Gurbantunggut desert is the second largest desert in China and is characterized by semi-mobile sand dunes [12]. This region has typical continental arid climatic features of scarce precipitation, intense evapotranspiration, windy, strong sunshine and severe variability of temperature [13]. Three study sites were selected near the southern edge of the Gurbantunggut desert: the desert ecosystem (DE), the transition ecosystem (TE) and the farmland ecosystem (FE) (Figure 1, Table 1). These three ecosystems were representative communities of this region, and were also set to form a transect from natural desert to cultivated land.

The desert ecosystem (DE) was located at $44^{\circ} 25^{\prime} \mathrm{N}, 87^{\circ} 54^{\prime} \mathrm{E}$. The annual mean temperature in this site is estimated to be $6^{\circ} \mathrm{C}-9^{\circ} \mathrm{C}$ and the annual mean precipitation is about $200 \mathrm{~mm}$, with a large annual evaporation around $2000 \mathrm{~mm}$ [14]. The dominant vegetation species is Haloxylon ammodendron, accompanied by only a few short-life vegetations in spring under the irrigation of snow melt water, and the total vegetation cover is less than 30\% [12] [15]. This site is mainly covered by aeolian sandy soil, which has a $\mathrm{pH}$ value about 8.5, a salinity content of $0.44 \mathrm{mg} / \mathrm{g}$ and an electrical conductivity (EC) around $0.14 \mathrm{~ms} / \mathrm{cm}[16]$.

The transition ecosystem (TE) was located at $44^{\circ} 17^{\prime} \mathrm{N}, 87^{\circ} 56^{\prime} \mathrm{E}$. This site belongs to Fukang station of Desert Ecology, Chinese Academy of Sciences. Its annual mean temperature is $5^{\circ} \mathrm{C}-7^{\circ} \mathrm{C}$ and annual precipitation is about $160 \mathrm{~mm}$, with an annual evaporation larger than $1700 \mathrm{~mm}$ [17]. The plant community is dominated by Tamarix spp., a deep rooted halophyte shrub, with canopy coverage of approximately $17 \%$ [18]. The soil is a silty clay loam with high salinity content about $17 \mathrm{mg} / \mathrm{g}$, electrical conductivity EC $>4 \mathrm{mS} / \mathrm{cm}$ and $\mathrm{pH}$ value around 8 [16] [19]. The salt is usually crystallized on the soil surface to form the white salt layer [16].

The farmland ecosystem (FE) was located at $44^{\circ} 17^{\prime} \mathrm{N}, 85^{\circ} 51^{\prime} \mathrm{E}$ in Shihezi oasis. This site belongs to the Wulanwusu Agrometeorological Station. Its annual mean temperature and precipitation is estimated to be $7^{\circ} \mathrm{C}$ and $210 \mathrm{~mm}$, respectively. The annual evaporation reaches to the value of $1600 \mathrm{~mm}$ [20]. Cotton is the major economic crop and is densely planted in the middle April and harvested in the middle of October. The soil texture is mainly sandy loam with the average soil bulk density of $1.30 \mathrm{~g} / \mathrm{cm}^{3}$ [20]. A noteworthy feature is that this site was characterized by different irrigation methods including drip irrigation and flood irrigation. Flood irrigation was conducted in the middle part of this sampling site about 20 days before the experiment. 

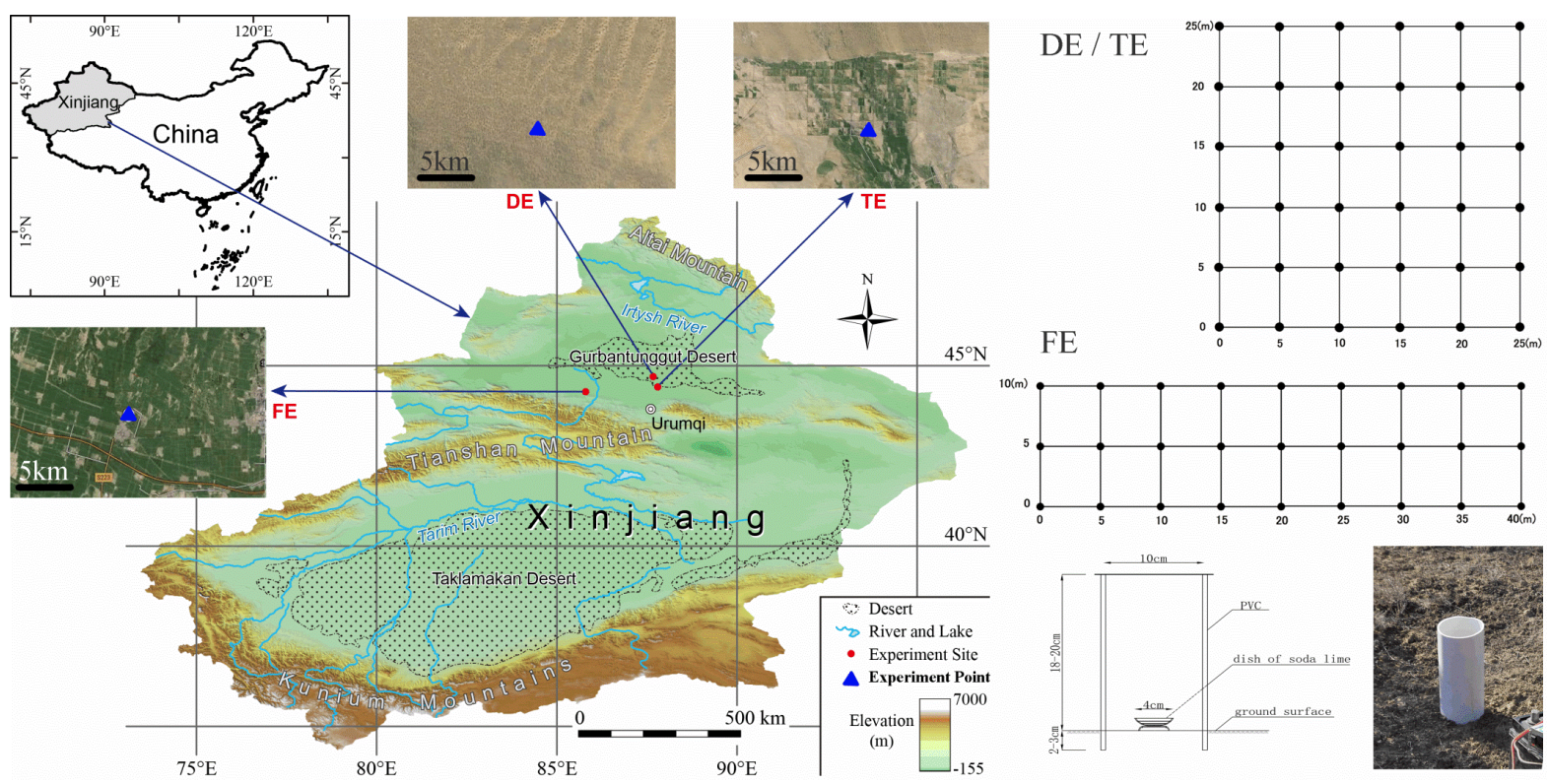

Figure 1. Location map of study sites and sampling designs. FE: farmland ecosystem, DE: desert ecosystem, TE: transition ecosystem. The black solid points stand for the sampling spots.

Table 1. Basic information of the three ecosystems—DE TE and FE.

\begin{tabular}{|c|c|c|c|c|c|c|c|}
\hline Ecosystems & Location & $\begin{array}{c}\text { Annual } \\
\text { temperature }\end{array}$ & $\begin{array}{c}\text { Annual } \\
\text { precipitation }\end{array}$ & $\begin{array}{c}\text { Annual } \\
\text { evaporation }\end{array}$ & $\begin{array}{l}\text { Dominant } \\
\text { plantation }\end{array}$ & Soil type & Management \\
\hline Desert (DE) & $\begin{array}{l}44^{\circ} 25^{\prime} \mathrm{N} \\
87^{\circ} 54^{\prime} \mathrm{E}\end{array}$ & $6^{\circ} \mathrm{C}-9^{\circ} \mathrm{C}$ & $200 \mathrm{~mm}$ & $2000 \mathrm{~mm}$ & $\begin{array}{c}\text { Haloxylon } \\
\text { ammodendron }\end{array}$ & $\begin{array}{l}\text { Sandy } \\
\text { soil }\end{array}$ & $\begin{array}{c}\text { Natural } \\
\text { No irrigation }\end{array}$ \\
\hline Transition (TE) & $\begin{array}{l}44^{\circ} 17^{\prime} \mathrm{N} \\
87^{\circ} 56^{\prime} \mathrm{E}\end{array}$ & $5^{\circ} \mathrm{C}-7^{\circ} \mathrm{C}$ & $160 \mathrm{~mm}$ & $1700 \mathrm{~mm}$ & Tamarix spp. & $\begin{array}{l}\text { Silty } \\
\text { clay } \\
\text { loam }\end{array}$ & $\begin{array}{l}\text { Semi-natural } \\
\text { No irrigation, } \\
\text { Adjacent to the } \\
\text { cultivated land }\end{array}$ \\
\hline Farmland (FE) & $\begin{array}{l}44^{\circ} 17^{\prime} \mathrm{N} \\
85^{\circ} 51^{\prime} \mathrm{E}\end{array}$ & $7^{\circ} \mathrm{C}$ & $210 \mathrm{~mm}$ & $1600 \mathrm{~mm}$ & Cotton & $\begin{array}{l}\text { Sandy } \\
\text { loam }\end{array}$ & $\begin{array}{c}\text { Artificially } \\
\text { management, } \\
\text { Irrigation }\end{array}$ \\
\hline
\end{tabular}

\subsection{Experimental Design and Soil Respiration Measurement}

In both DE and TE sites, 36 soil sampling pixels were set up in late August 2012 at a $5 \times 5 \mathrm{~m}$ grid. The FE was investigated in early September of 2013 and 27 soil sampling pixels were set up at a $5 \mathrm{~m}$ resolution within a $10 \times$ $40 \mathrm{~m}$ plot subject to local conditionality (Figure 1). Although different sampling strategies were adopted between DE/TE and FE, each sampling design could reflect the respective spatial characteristic of the three sites. The experimental dates were decided when soil temperature and soil moisture are approaching their annual average levels.

Soil respiration was measured using soda lime absorption method followed the protocol of Keith and Wong [21], which enabled us to conduct a number of measurements simultaneously. In all three ecosystems, soil respiration was measured continuously over a $24 \mathrm{~h}$ sampling period to provide a mean daily rate $\left(\mathrm{gC} / \mathrm{m}^{2} / \mathrm{d}\right)$. Before the measurements, the chambers (made of PVC collar with an area of $86 \mathrm{~cm}^{2}$ and a volume of $1800 \mathrm{~cm}^{3}$ ) were inserted into the soil surface to a depth of approximately $2 \mathrm{~cm}$ several days ahead of time when soda lime was placed in order to avoid effects of soil disturbance. The aerial part of live vegetation inside the chambers was also removed to prevent $\mathrm{CO}_{2}$ uptake. Soda lime in granules of $2-4 \mathrm{~mm}$ mesh size was used. Approximately 15 $\mathrm{g}$ (in DE and TE, $25 \mathrm{~g}$ in FE) of soda lime per dish (aluminum dish with an area of $19.6 \mathrm{~cm}^{2}$ and a lid) was oven-dried at $105^{\circ} \mathrm{C}$ for $20 \mathrm{~h}$ until reaching a constant weight. The soda lime loaded dishes were weighed in order to record exact initial dry weights. Then the soda lime was rewetted using a spray and the dishes were cov- 
ered with lids, put into airtight plastic bags and transported to the fields. Afterwards, we placed the dish on the soil surface inside the chamber, removed the lid of the dish and finally sealed the chamber tightly with plastic membrane. The closing and opening time of each chamber was recorded to exactly determine the absorption period.

After having absorbed $\mathrm{CO}_{2}$ emitted from soil for about $24 \mathrm{~h}$, dishes were taken out and covered immediately before transported to the laboratory promptly, in which they were oven-dried at $105^{\circ} \mathrm{C}$ to constant values for reweighing. In order to reduce experimental errors, soda lime was handled with care to prevent extra exposure to the air during the entire measurement period. Moreover, blank measurements were made to account for $\mathrm{CO}_{2}$ that was not released by soil respiration but yet absorbed by soda lime during the experimental procedure: dishes with the same weight of soda lime which underwent the entire procedure of drying and weighing, were placed in blank chambers and left for the same period in the field to simulate conditions of the incubating chambers [21].

The calculation formula is based on Keith and Wong [21]:

$$
\begin{aligned}
& \text { Soil } \mathrm{CO}_{2} \text { efflux }\left(\mathrm{g} \mathrm{C} \mathrm{m}^{-2} \cdot \text { day }^{-1}\right) \\
& =\frac{[(\text { sample weigh gain }(\mathrm{g})-\text { mean blank weight gain }(\mathrm{g})) \times 1.69]}{\text { chamber area }\left(\mathrm{m}^{2}\right)} \\
& \quad \times \frac{24(\mathrm{~h})}{\text { duration of exposure }(\mathrm{h})} \times \frac{12}{44} .
\end{aligned}
$$

\subsection{Measurements of Environmental Factors}

Along with soil respiration measurements, several controlling environmental factors were also recorded during the sampling periods. Soil moisture (SM), soil dielectric constant ( $(\mathrm{b})$ ), pore water conductivity (ECp), electrical conductivity (ECb) and soil surface temperature (ST) were measured using time domain reflectometry (TDR, Delta-T Devices, Cambridge, England). Additionally, ST was also measured using an infrared video thermography of FLIR CPA 0170 (FLIR Systems, Wilsonville, OR, USA). However, the data of ECp in DE and TE, and the ECb data in DE were not recorded accurately and thus eliminated from further analysis.

\subsection{Statistical Analysis}

Descriptive statistics including mean value, standard deviation (SD) and coefficient of variation (CV) were calculated and one-way analysis of variance (ANOVA) and Tukey's HSD test were used to verify whether there were significant differences among the mean values at the 95\% confidence levels. The correlations between SR and ST, SR and SM, as well as SR and soil electrical conductivity were analyzed using Pearson correlation method.

Geostatistics were then used to evaluate spatial variation in these ecosystems. Geostatistics allow for the determination of the magnitude of spatial dependence and the scale of spatial autocorrelation among measurement points [22] [23]. The central tool in geostatistics is the semivariance statistic. The calculation of semivariances was performed using the geostatistics software GS+ (Gamma Design, 1995) and was estimated by the equation:

$$
\gamma(h)=\frac{1}{2 N(h)} \sum_{i=1}^{n}\left[z\left(s_{i}\right)-z\left(s_{i}+h\right)\right]^{2}
$$

where $N(h)$ is the number of measurement pairs separated by distance $h, z\left(s_{i}\right)$ is the value of the variable of interest at location $s_{i}$, and $z\left(s_{i}+h\right)$ is its value at a location at distance $h$ from $s_{i}$ [24]. Graphing the semivariance values across all separation distances provided the semivariogram [25]. A typical semivariogram has a nugget variance $\left(\mathrm{C}_{0}\right)$ and the variance will increase up to the sill variance $\left(\mathrm{C}_{0}+\mathrm{C}\right)$ with increasing separation distance. The distance where the sill reaches is called the range. The measurement points estimated within this range are spatially autocorrelated, otherwise points outside this range are deemed independent [22] [26]. The proportion of the nugget variance $\left(\mathrm{C}_{0}\right)$ to sill variance $\left(\mathrm{C}_{0}+\mathrm{C}\right)$ is calculated to evaluate the magnitude of the spatial dependence [22] [27]-[29]. 


\section{Results}

\subsection{Descriptive Statistics of SR and Controlling Factors}

For the three ecosystems, the statistical results of the SR and respective controlling factors of the three ecosystems were summarized in the Table 2, and the comparison of SR, ST and SM were showed in the Figure 2. The average value of soil respiration of TE was the highest $\left(0.166 \mathrm{gC} / \mathrm{m}^{2} / \mathrm{h}\right)$ among the three sites, almost two times higher than the value of DE $\left(0.061 \mathrm{gC} / \mathrm{m}^{2} / \mathrm{h}\right)$, but only slightly higher than that of $\mathrm{FE}\left(0.147 \mathrm{gC} / \mathrm{m}^{2} / \mathrm{h}\right)$. Considering the CV values of SR, TE had the maximum (57.8\%), while DE (29.5\%) was approximately at the same low level with that in FE (27.2\%), indicating that the variation of SR in TE was much significant than in the other two ecosystems. The difference of soil moisture among the three ecosystems was also remarkable, with the value of $20.1 \%$ in FE, much greater than that of TE $(9.70 \%)$ or DE (4.18\%). However, TE presented the most significant CV value of $46.5 \%$, suggesting the largest variation of soil moisture in this ecosystem.

Soil electrical conductivity (ECb) of DE could not have been detected precisely using TDR, mainly because of the extremely low salinity content close to zero $(<0.5 \mathrm{mS} / \mathrm{m})$ in this area [16], as the resolution of TDR on ECb was $1.0 \mathrm{mS} / \mathrm{m}$. Although in FE, ECb value was obviously larger than that in TE, the CV values of both two ecosystems were very similar. The average values of soil surface temperature in three ecosystems were different to each other, but their CV values remained relatively low levels (5.40\% in DE, 7.40\% in TE and 10\% in FE), indicating that temperature was less variable in all three ecosystems. Small CV values of ST and large CV values of SR and SM suggested that the effect of soil temperature on SR variation was not significant, whereas the soil moisture may play a more important role in these arid ecosystems.

\subsection{Correlations between SR and Controlling Factors}

Scatter diagrams between SR and environmental factors of the three ecosystems were presented in Figure 3.

Table 2. Summary of SR and controlling factors in each ecosystem.

\begin{tabular}{|c|c|c|c|c|c|c|}
\hline \multirow{2}{*}{ Variables } & \multicolumn{2}{|c|}{$\begin{array}{l}\text { Desert Ecosystem } \\
\text { (DE) } n=36\end{array}$} & \multicolumn{2}{|c|}{$\begin{array}{l}\text { Transition Ecosystem } \\
\text { (TE) } n=36\end{array}$} & \multicolumn{2}{|c|}{$\begin{array}{l}\text { Farmland Ecosystem } \\
\text { (FE) } n=27\end{array}$} \\
\hline & Mean \pm SD & CV (\%) & Mean \pm SD & CV (\%) & Mean \pm SD & CV (\%) \\
\hline $\begin{array}{l}\text { Soil Respiration } \\
\left(\mathrm{SR}, \mathrm{gC} / \mathrm{m}^{2} / \mathrm{h}\right)\end{array}$ & $0.061 \pm 0.003^{\mathrm{a}}$ & 29.50 & $0.160 \pm 0.33^{\mathrm{b}}$ & 57.80 & $0.147 \pm 0.008^{\mathrm{a}}$ & 27.20 \\
\hline $\begin{array}{l}\text { Soil Temperature } \\
\qquad\left(\mathrm{ST},{ }^{\circ} \mathrm{C}\right)\end{array}$ & $22.5 \pm 0.204^{\mathrm{a}}$ & 5.40 & $30 \pm 0.369^{c}$ & 7.40 & $27.3 \pm 0.516^{\mathrm{b}}$ & 10 \\
\hline $\begin{array}{l}\text { Soil Moisture } \\
\text { (SM, \%) }\end{array}$ & $4.18 \pm 0.124^{\mathrm{a}}$ & 17.90 & $9.70 \pm 0.752^{\mathrm{b}}$ & 46.50 & $20.1 \pm 1.302^{\mathrm{c}}$ & 33.80 \\
\hline $\begin{array}{c}\text { Electrical } \\
\text { Conductivity } \\
\text { (ECb mS/m) }\end{array}$ & - & - & $6.31 \pm 1.638^{\mathrm{a}}$ & 36.10 & $13.22 \pm 2.168^{b}$ & 35.40 \\
\hline
\end{tabular}

Mean \pm SD, n = 36, 36 and 27 for DE, TE and FE, different letters indicate significant differences (ANOVA, Tukey’s b test, $P<0.05$ ). CV: Coefficient of variation.
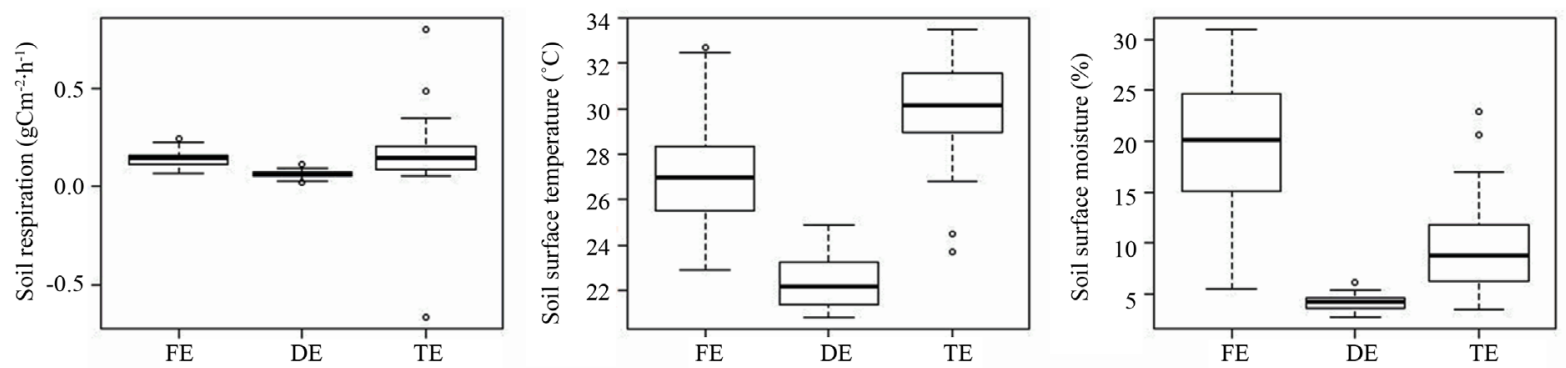

Figure 2. Comparison of SR, ST and SM over three different ecosystems. Boxes encompass the $25 \%$ and $75 \%$ quartiles of the entire dataset. The central solid line represents the median, bars extend to the 95\% confidence limits, and the dots represent outliers. FE, DE and TE represent farmland ecosystem, desert ecosystem and transition ecosystem, respectively. 

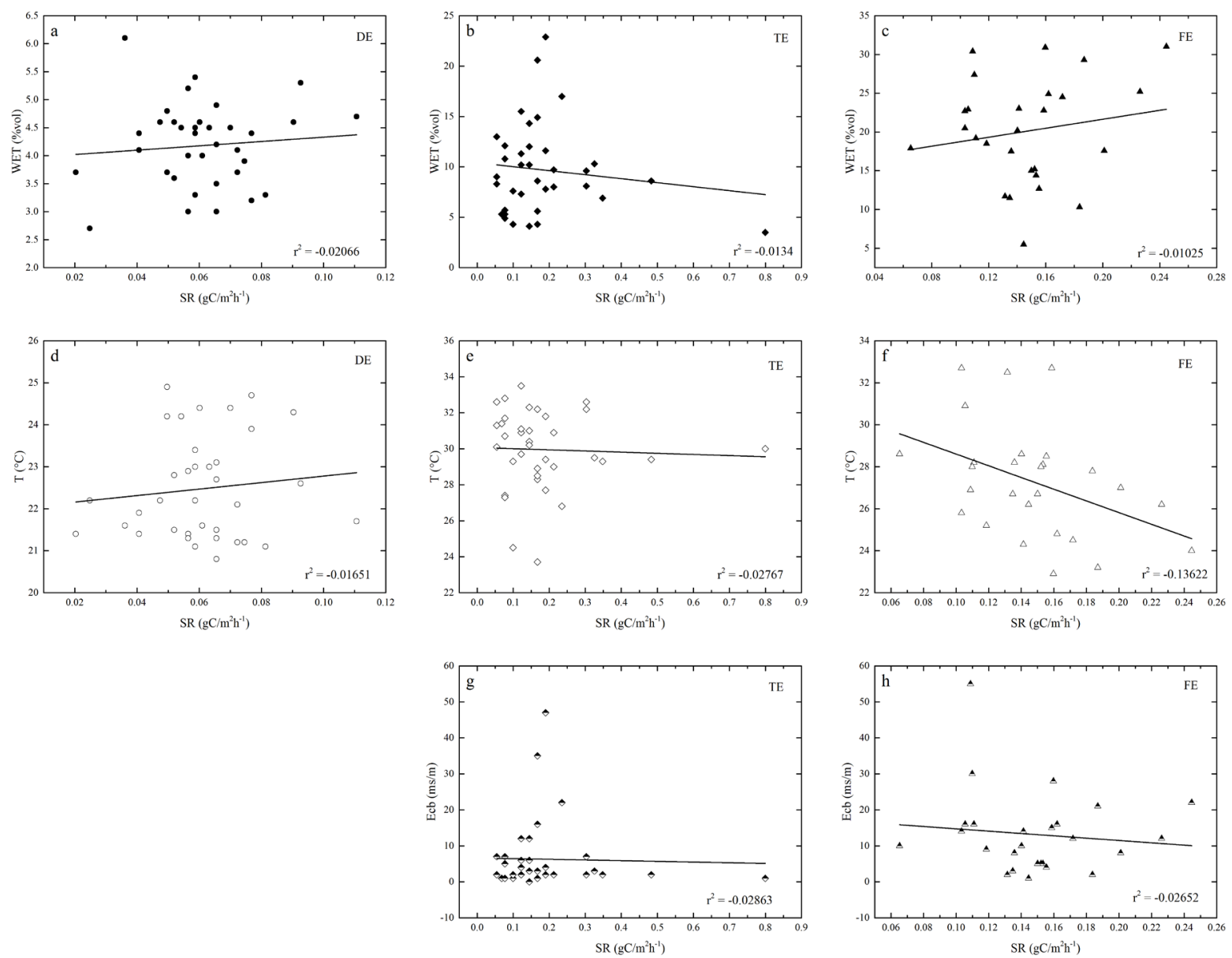

Figure 3. Scatter diagrams between SR and environmental factors of the three ecosystems. FE, DE and TE represent farmland ecosystem, desert ecosystem and transition ecosystem, respectively.

Correlation analysis (Table 3) suggested that in DE, there was no significant correlation between soil respiration and environmental factors, indicating that no single factor could adequately explain the variation of soil respiration. In this area, the soil electrical conductivity value approached zero, indicating rather low salinity content of the soil. Similar situation was also found in TE, with no significant correlations between soil respiration and environmental factors being identified. However, significant negative correlation was found between soil temperature and soil moisture $(P<0.05)$, as well as between soil temperature and soil electrical conductivity $(\mathrm{ECb})(P<$ 0.01 ) in TE, with values of -0.381 and -0.482 , respectively. In addition, the correlations between soil moisture and soil electrical conductivity (ECb) were highly significant in all the cases $(P<0.01)$, suggesting the strong correlation between the two parameters.

In FE, the correlation of soil respiration and soil temperature had a negative value of $-0.412(P<0.05)$, indicating that increasing of soil surface temperature may lead to a decline of soil respiration rate in this area. For all three ecosystems, soil respiration had positively correlations with both soil temperature and soil moisture $(P<$ 0.05 ), but no significant relationship was found with soil electrical conductivity.

\subsection{Spatial Structures of SR and Controlling Factors}

Semivariograms of soil respiration rates, soil temperature, soil moisture and soil ECb of the three ecosystems are given in the Figure 4. Furthermore, the key parameters of semivariograms are shown in the Table 4. The optimal model of SR semivariogram was found to be a linear model, while Gaussian model for soil temperature and spherical models for both soil moisture and soil ECb fit best. In general, most models had high coefficients of determination, as judged from their $\mathrm{R}^{2}$ values. 
Table 3. Correlations between SR and controlling factors of the three ecosystems.

\begin{tabular}{|c|c|c|c|c|c|}
\hline & & SR & ST & SM & $\mathrm{ECb}$ \\
\hline \multirow{4}{*}{$\begin{array}{c}\text { Desert } \\
\text { Ecosystem }\end{array}$} & SR & 1.000 & & & \\
\hline & $\mathrm{ST}$ & 0.016 & 1.000 & & \\
\hline & SM & 0.095 & 0.300 & 1.000 & \\
\hline & $\mathrm{ECb}$ & - & - & - & \\
\hline \multirow{4}{*}{$\begin{array}{l}\text { Transition } \\
\text { Ecosystem }\end{array}$} & SR & 1.000 & & & \\
\hline & ST & -0.098 & 1.000 & & \\
\hline & SM & 0.014 & $-0.381^{*}$ & 1.000 & \\
\hline & $\mathrm{ECb}$ & -0.270 & $-0.482^{* *}$ & $0.886^{* *}$ & 1.000 \\
\hline \multirow{4}{*}{$\begin{array}{l}\text { Farmland } \\
\text { Ecosystem }\end{array}$} & SR & 1.000 & & & \\
\hline & ST & $-0.412^{*}$ & 1.000 & & \\
\hline & SM & 0.169 & -0.379 & 1.000 & \\
\hline & $\mathrm{ECb}$ & -0.113 & -0.224 & $0.809^{* *}$ & 1.000 \\
\hline \multirow{4}{*}{ Total } & SR & 1.000 & & & \\
\hline & $\mathrm{ST}$ & $0.237^{*}$ & 1.000 & & \\
\hline & SM & $0.211^{*}$ & $0.248^{*}$ & 1.000 & \\
\hline & $\mathrm{ECb}$ & 0.160 & 0.140 & $0.836^{* *}$ & 1.000 \\
\hline
\end{tabular}

${ }^{*}$ and ${ }^{* *}$ indicate significant correlations at $P<0.05$ and $P<0.01$, respectively. SR: soil respiration rate; ST: soil surface temperature; SM: soil moisture; ECb: soil electrical conductivity.

Table 4. Summary of semivariogram model parameters for soil respiration and controlling factors.

\begin{tabular}{|c|c|c|c|c|c|c|c|c|}
\hline Variables & Model & Ecosystem & Nugget variance (C) & $\begin{array}{l}\text { Sill variance } \\
\quad\left(C_{0}+C\right)\end{array}$ & Range $A_{0}(m)$ & $\mathrm{C} /\left(\mathrm{C}_{0}+\mathrm{C}\right)$ & RSS & $\mathrm{R}^{2}$ \\
\hline \multirow[t]{3}{*}{ SR } & Linear & $\mathrm{DE}$ & 0.000337 & 0.000371 & 16.35 & 0.907 & $7.188 \mathrm{E}-11$ & 0.770 \\
\hline & & $\mathrm{TE}$ & 0.012939 & 0.020800 & 16.35 & 0.622 & $6.740 \mathrm{E}-07$ & 0.949 \\
\hline & & $\mathrm{FE}$ & 0.000836 & 0.001802 & 16.03 & 0.464 & $1.358 \mathrm{E}-09$ & 0.993 \\
\hline \multirow[t]{3}{*}{$\mathrm{ST}$} & Gaussian & $\mathrm{DE}$ & 0.038 & 2.186 & 15.53 & 0.017 & 0.008151 & 0.989 \\
\hline & & $\mathrm{TE}$ & 0.870 & 5.708 & 4.03 & 0.152 & 0.463 & 0.308 \\
\hline & & $\mathrm{FE}$ & 1.290 & 11.589 & 12.72 & 0.111 & 0.422 & 0.988 \\
\hline \multirow[t]{3}{*}{ SM } & Spherical & $\mathrm{DE}$ & 0.055 & 0.613 & 9.03 & 0.090 & 0.004792 & 0.514 \\
\hline & & $\mathrm{TE}$ & 1.410 & 21.800 & 8.33 & 0.065 & 5.660 & 0.379 \\
\hline & & $\mathrm{FE}$ & 0.1 & 70.2 & 25.59 & 0.001 & 29.100 & 0.976 \\
\hline \multirow[t]{3}{*}{$\mathrm{ECb}$} & Spherical & $\mathrm{DE}$ & - & - & - & - & - & - \\
\hline & & $\mathrm{TE}$ & 16.3 & 113 & 8.44 & 0.144 & 94.700 & 0.479 \\
\hline & & $\mathrm{FE}$ & 11.7 & 166.5 & 17.43 & 0.070 & 0.119 & 1 \\
\hline
\end{tabular}

We have also calculated the proportion of nugget to sill to evaluate the magnitude of the spatial dependence in each site. As a rule of thumb, strong spatial autocorrelation occurs when the proportion is lower than 0.25 , and moderate autocorrelation happened when the proportion is within the range of 0.25 and 0.75 , and weak autocorrelation with the proportion larger than 0.75 [30]. From the Table 4, the value of nugget to sill for SR in DE was 0.907 , followed by 0.62 in TE and 0.46 in FE. This suggested that a very weak spatial dependence occurred in the desert ecosystem, indicating a rather homogeneous or random spatial structure in this site, while moderate spatial dependences were found in both TE and FE sites. From DE to TE and FE, the spatial dependence was 

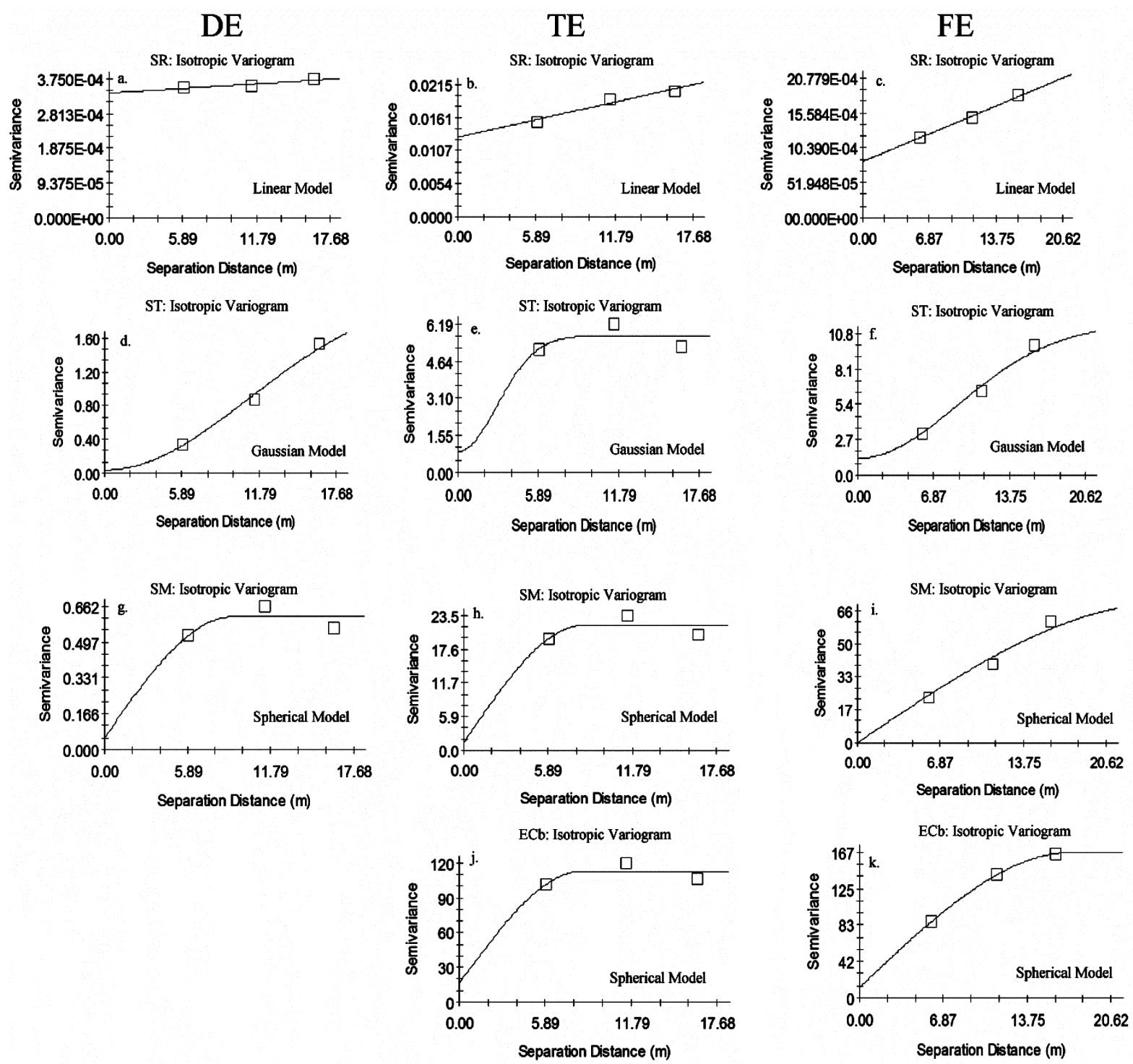

Figure 4. Semivarigrams for soil respiration (SR), soil temperature (ST), soil moisture (SM) and soil electrical conductivity (ECb) of the three ecosystems.

becoming stronger and the spatial heterogeneity was gradually getting apparent. In both DE and TE, the spatial dependence of SR was mainly affected by random factors, especially in DE because they had relative large nugget values, whereas in FE, the structural factors mainly accounted for the spatial dependence. The ranges of spatial dependence of the three ecosystems were all about $16 \mathrm{~m}$, indicating that the spatial dependence of soil respiration rates occurred almost within the same scale.

Semivariograms of soil moisture had a range of $9.03 \mathrm{~m}, 8.33 \mathrm{~m}$ and $25.59 \mathrm{~m}$ in DE, TE and FE, respectively, suggesting that the spatial dependence of soil moisture varied in different scales among different ecosystems. According to the semivariogram of soil moisture in FE, the patchy distribution of soil moisture was seldom appeared, and the heterogeneity was large and smoothly continuous, reflecting a gradual changing structure, which was probably owing to the zonal distribution of cotton plantation. As a comparison, obvious patchy structures and more shapely discontinuity were identified in DE and TE, reflecting hot and cold spots of the measured values [24], as showed in the Figure 5. This heterogeneity was mainly attributed to the patchy distribution of the plantation of Haloxylon in DE and Tamarix spp. in TE. Additionally, the difference of ECb between TE and FE showed similar situations with soil moisture. 

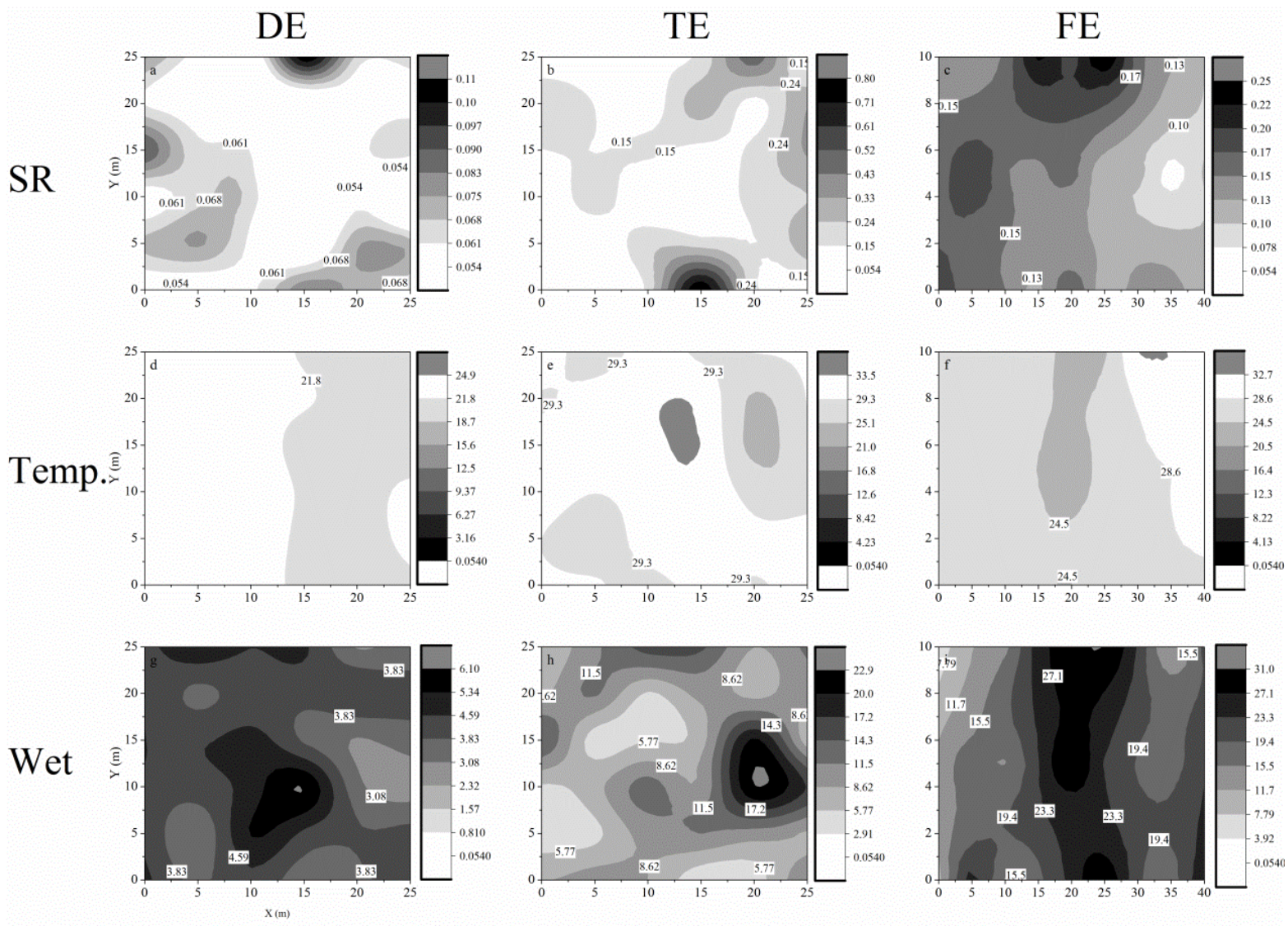

\section{$\mathrm{ECb}$}
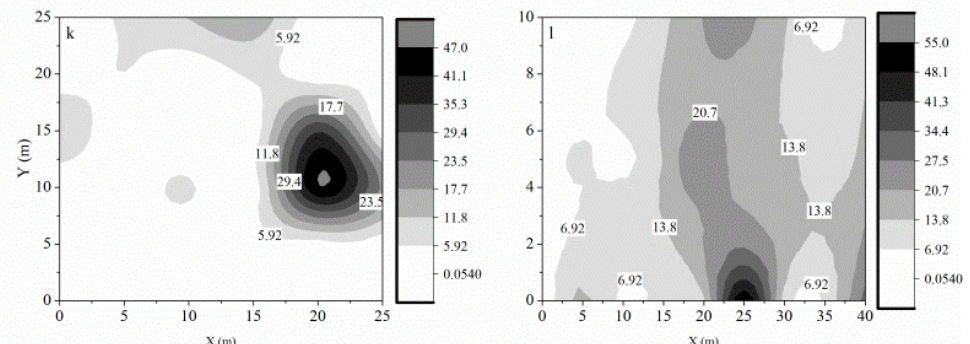

Figure 5. Isopleths for the soil respiration (SR), the soil temperature (ST), the soil moisture(SM) and the soil electrical conductivity (ECb) of the three ecosystems.

\section{Discussion}

\subsection{Soil Respiration and Environmental Factors}

Although the soda lime method, which was used to measure the daily average soil respiration rates over three arid ecosystems in this study, remains disputable about its accuracy, e.g. non-flow through chambers tended to have higher values due to absorption of $\mathrm{CO}_{2}$ in the headspace to below ambient concentrations [21], we are relatively confident about our results since a number of similar counterparts were reported. For instance, soil respiration rate of TE was found to be comparable to those reported in similar ecosystems [7] [19] [20] [31], while the soil respiration in FE was parallel with the results of Zhang, et al. [32] and Bai, et al. [33]. Even in DE, soil respiration also had a similar order of magnitude with the data from the review of Raich and Schlesinger [6] and Cable, et al. [34] [35]. Although flow-through non-steady-state (FS-NSS) IRGA method are widely used to continuously measure soil respiration rate nowadays, simultaneous measurements of a large number of replicates still require this traditional soda lime absorption method be applied.

Soil temperature and soil water content are commonly considered to be the key environmental factors that re- 
sponsible for variation in soil respiration [3] [36] [37]. Fluctuations of soil temperature and/or soil moisture can well explain the temporal variation of soil respiration, both diurnally and seasonally. Furthermore, a combination of soil temperature and soil water content can usually improve the estimation of soil respiration. For example, the sensitivity of soil respiration to temperature frequently increases as soil water content increases [38][40]. However, opposite cases were also identified, e.g. high soil temperature suppressed soil respiration which was mainly because of drought stress nearby TE site as found by Naramoto and Wang [41].

However, it seems that no single factor can explain the spatial variation adequately as compared with the temporal variation [40] [42]. Spatial variation of soil respiration could occur dramatically even within small distance of centimeters [43], and there tends to be no factor which can be solely responsible for such substantial heterogeneity correspondingly. Similarly, in our case, no significant correlation between soil respiration and controlling environmental factors were found in both DE and TE sites, identical to the results from Panosso's research [44]. Significant relationships were reported for spatial variation of SR and soil moisture [7] [45] [46], $\mathrm{C} / \mathrm{N}$ ratio and topsoil bulk density jointly [43], plant root and plant residue patterns [25] in previous studies, but the correlation between spatial variation of SR with single soil temperature or soil moisture was barely reported, suggesting that when spatial variation is investigated, soil properties and/or vegetation information should be paid more attention to beyond soil temperature and soil moisture.

Sampling size may be another important aspect that having determined the correlations between SR and environmental factors. Larger sampling sizes generally permit more accurate estimations, but often limited by labor or time constraints, and also depend on the spatial heterogeneity of soil respiration rates [47]. In current study, only 36 or 27 sampling pixels were established in each ecosystem, which may not be sufficient. However, when all the data of the three ecosystems were combined together, correlations between SR and controlling factors emerged, suggesting that sampling size may need to be properly determined.

\subsection{Spatial Variations of Soil Respiration in Three Ecosystems}

Spatial variation of soil respiration occurs at various scales, from a few square centimeters to several hectares up to the globe [48] [49]. Compared with temporal variation of soil respiration, which can be frequently well explained by environment factors such as soil temperature and soil moisture, the spatial variation of SR tends to be more complicated because of its high spatial variation, especially in semiarid and arid areas [8] [10]. As a result, there are always cases that no evident controlling factor could be detected with significant spatial variations, except that variables related to forest structure may have explained some of the variation of soil respiration [50]. Generally, different positions apart from a plant have been investigated for spatial heterogeneity of SR in arid ecosystems, in which the existence of vegetation might play an important role in manipulating the spatial heterogeneity [10] [11], e.g., Ma, et al. [19] designed an experiment in an adjacent site near TE to measure SR rates along a transect from the site near plant stem to the interplant space to capture individual-based variation and suggested that SR rates decreased with the increase of distance away from the plant stem. In addition, Wang, et al. [45] found that the location of the high value positions of soil moisture, soil microbial biomass carbon and soil respiration were clearly around the positions of scrubs. Furthermore, Stoyan, et al. [25] estimated that the main causes of soil heterogeneity around poplar trees were likely to be controlled in part by root and plant at micro scales.

Alternatively, we aimed to provide a meaningful reference considering the larger plot scale heterogeneity of soil respiration. In this study, we compared the spatial variation of soil respiration under three different ecosystems and found distinctly different degree of spatial variation among them. Soil respiration in the TE had a great variance with the CV of 57.8\%, much larger than those of DE (29.5\%) and FE (27.2\%). Compared to DE and FE, the soil surface of TE may exhibit a more "patchy" structure feature [11] [43]. In this site, the predominant plantations of Tamarix spp. were sturdy with larger diameter at breast height (DBH) and basal area (BA), which were scattered to develop "islands of fertility" phenomenon. Besides soil respiration rate, the CV of soil temperature, soil moisture and soil electrical conductivity in TE were all larger than in DE and FE, indicating the most significant heterogeneity among the three ecosystems. In DE, Haloxylon ammodendron was relatively scarce with lower productivity. Soil respiration was weak and less influenced by the distribution pattern compared with TE.

Although the descriptive statistics (SD and CV) are the first indicators of spatial variation, they cannot reveal the real situation of spatial heterogeneity because no information on the points of the spatial distribution is 
available [9] [44]. Hence, geostatistics were employed in this study to figure out their spatially structured phenomena which may provide a means for defining the magnitude of spatial dependence and the scale of autocorrelation [22] [26]. As a central tool in geostatistics, the semivariance statistic is extensively applied to evaluate the spatial heterogeneity of soil respiration in forest ecosystems [25] [26] [48] or farmland ecosystems [7] [44], but there are few reports using geostatistical analysis to clarify the spatial structure of soil respiration in the arid desert ecosystems. Wang, et al. [45] conducted an experiment in an area adjacent to the our TE site which contained 42 sampling points with $2 \mathrm{~m}$ grids and found a moderate spatial autocorrelation of SR with the nugget to sill value of 0.49 and a range of $4.78 \mathrm{~m}$, compared with our more homogeneous distribution as deduced from larger nugget/sill value of 0.62 and range of $16.35 \mathrm{~m}$. It is reported that the range of spatial variation models of SR changed temporally [25] [26] [51] and could also be affected by the plot size [52], which might account for the discrepancy.

Topography and vegetation conditions in the monoculture plantations were relatively homogeneous [47]. However, in our case, based on geostatistic method rather than CV values, the spatial heterogeneity of the cotton field (FE) exhibited most significantly, probably due to the different irrigation management within this site. Our sampling points spread on the site which was characterized by two different irrigation methods including drip irrigation and flood irrigation, and flood irrigation was conducted in the middle part of this sampling site about 20 days before the experiment, which could dramatically change the soil properties and generate inhomogeneity of SR rates in this area. As the Figure 5 showed, soil moisture and soil respiration were significantly larger in the middle area where irrigation was conducted. Compared to DE and TE, which presented the patchy structure of soil respiration and soil moisture, FE tended to show zonal distribution (see the Figure 5) mainly owing to the vegetation and irrigation characteristics. In summary, although CV values showed that TE had the largest variation, we believe that the more reliable geostatistic method provided the real spatial heterogeneity status, with the order of significance as FE $>$ TE $>$ DE.

\section{Conclusion}

Geostatistical analysis offers a reliable method to investigate the spatial variation of soil respiration. Soil respiration in desert ecosystem tends to show relatively small spatial variation owing to the homogeneous structure of soil properties. While in transition area, larger xerophytes may play a more important role in controlling the spatial pattern of soil surface properties including soil respiration. In arid region, irrigation is necessary for agriculture production, which can result in significant change in soil respiration. Soil moisture may be the decisive factor in many occasions in this drought area, but different from temporal variation, multiple factors are needed to verify the spatial variation of soil respiration.

\section{Acknowledgements}

We are grateful to L. Xu, H. Guan and B. Liu of Xinjiang Institute of Ecology and Geography, Chinese Academy of Sciences for their help with fieldwork. We would like to thank Z. Cao, and S, Lu for their review and suggestions.

\section{References}

[1] Bouwman, A. and Germon, J. (1998) Soil and Global Change (Special Issue)—Introduction. Biology and Fertility of Soil, 27, 219.

[2] Rustad, L.E., Huntington, T.G. and Boone, R.D. (2000) Controls on Soil Respiration: Implications for Climate Change. Biogeochemistry, 48, 1-6. http://dx.doi.org/10.1023/A:1006255431298

[3] Fang, C. and Moncrieff, J.B. (2001) The Dependence of Soil $\mathrm{CO}_{2}$ Efflux on Temperature. Soil Biology \& Biochemistry, 33, 155-165. http://dx.doi.org/10.1016/S0038-0717(00)00125-5

[4] Reynolds, J.F. (2001) Desertification. Encyclopedia of Biodiversity, 2, 61-78. http://dx.doi.org/10.1006/rwbd.1999.0072

[5] Conant, R.T., Klopatek, J.M. and Klopatek, C.C. (2000) Environmental Factors Controlling Soil Respiration in Three Semiarid Ecosystems. Soil Science Society of America Journal, 64, 383-390. http://dx.doi.org/10.2136/sssaj2000.641383x

[6] Raich, J.W. and Schlesinger, W.H. (1992) The Global Carbon-Dioxide Flux in Soil Respiration and Its Relationship to 
Vegetation and Climate. Tellus Series B-Chemical and Physical Meteorology, 44, 81-99. http://dx.doi.org/10.1034/j.1600-0889.1992.t01-1-00001.x

[7] Zhang, L.H., Chen, Y.N., Zhao, R.F. and Li, W.H. (2010) Significance of Temperature and Soil Water Content on Soil Respiration in Three Desert Ecosystems in Northwest China. Journal of Arid Environments, 74, 1200-1211. http://dx.doi.org/10.1016/j.jaridenv.2010.05.031

[8] Maestre, F.T. and Cortina, J. (2003) Small-Scale Spatial Variation in Soil $\mathrm{CO}_{2}$ Efflux in a Mediterranean Semiarid Steppe. Applied Soil Ecology, 23, 199-209. http://dx.doi.org/10.1016/S0929-1393(03)00050-7

[9] Fang, C., Moncrieff, J.B., Gholz, H.L. and Clark, K.L. (1998) Soil $\mathrm{CO}_{2}$ Efflux and Its Spatial Variation in a Florida Slash Pine Plantation. Plant and Soil, 205, 135-146. http://dx.doi.org/10.1023/A:1004304309827

[10] Schlesinger, W.H. and Pilmanis, A.M. (1998) Plant-Soil Interactions in Deserts. Biogeochemistry, 42, 169-187. http://dx.doi.org/10.1023/A:1005939924434

[11] Titus, J.H., Nowak, R.S. and Smith, S.D. (2002) Soil Resource Heterogeneity in the Mojave Desert. Journal of Arid Environments, 52, 269-292. http://dx.doi.org/10.1006/jare.2002.1010

[12] Zheng, C. and Wang, Q. (2014) Water-Use Response to Climate Factors at Whole Tree and Branch Scale for a Dominant Desert Species in Central Asia: Haloxylon ammodendron. Ecohydrology, 7, 56-63. http://dx.doi.org/10.1002/eco.1321

[13] Zhang, L. and Chen, C. (2001) On the General Characteristics of Plant Diversity of Gurbantunggut Sandy Desert. Acta Ecologica Sinica, 22, 1923-1932.

[14] Luo, G.P., Zhou, C.H., Chen, X. and Li, Y. (2008) A Methodology of Characterizing Status and Trend of Land Changes in Oases: A Case Study of Sangong River Watershed, Xinjiang, China. Journal of Environmental Management, 88, 775-783. http://dx.doi.org/10.1016/j.jenvman.2007.04.003

[15] Zhang, P., Dong, Y., Wei, Y. and Hu, C. (2006) ISSR Analysis of Genetic Diversity of Haloxylon ammodendron (CA Mey.) Bunge in Xinjiang. Acta Botanica Boreali-Occidentalia Sinica, 26, 1337.

[16] Guan, H.-Y., Wang, Q. and Zhao, X. (2015) Seasonal Patterns of Soil Microbial Biomass C and Impacting Factors in Two Typical Arid Desert Vegetation Regions. Arid Land Geography, 38, 67-75. (In Chinese with English Abstract)

[17] Wang, Y., Xiao, D. and Li, Y. (2008) Spatial and Temporal Dynamics of Oasis Soil Salinization in Upper and Middle Reaches of Sangonghe River, Northwest China. Journal of Desert Research, 28, 478-484.

[18] Xu, H., Li, Y., Xu, G.Q. and Zou, T. (2007) Ecophysiological Response and Morphological Adjustment of Two Central Asian Desert Shrubs towards Variation in Summer Precipitation. Plant Cell and Environment, 30, 399-409. http://dx.doi.org/10.1111/j.1365-3040.2006.001626.X

[19] Ma, J., Zheng, X.J. and Li, Y. (2012) The Response of $\mathrm{CO}_{2}$ Flux to Rain Pulses at a Saline Desert. Hydrological Processes, 26, 4029-4037. http://dx.doi.org/10.1002/hyp.9204

[20] Wang, J., Bai, J. and Wang, S.M. (2013) The Effects of Mulched with Dripping on Carbon and Water Dynamics by Cotton in Northwest China. 2013 International Conference on Agricultural and Natural Resources Engineering (ICANRE 2013), 5, 14-20. http://dx.doi.org/10.1016/j.ieri.2013.11.064

[21] Keith, H. and Wong, S.C. (2006) Measurement of Soil $\mathrm{CO}_{2}$ Efflux Using Soda Lime Absorption: Both Quantitative and Reliable. Soil Biology \& Biochemistry, 38, 1121-1131. http://dx.doi.org/10.1016/j.soilbio.2005.09.012

[22] Robertson, G.P. (1987) Geostatistics in Ecology: Interpolating with Known Variance. Ecology, 68, 744-748. http://dx.doi.org/10.2307/1938482

[23] Goovaerts, P. (1998) Geostatistical Tools for Characterizing the Spatial Variability of Microbiological and Physico-Chemical Soil Properties. Biology and Fertility of Soils, 27, 315-334. http://dx.doi.org/10.1007/s003740050439

[24] Ettema, C.H. and Wardle, D.A. (2002) Spatial Soil Ecology. Trends in Ecology \& Evolution, 17, 177-183. http://dx.doi.org/10.1016/S0169-5347(02)02496-5

[25] Stoyan, H., De-Polli, H., Bohm, S., Robertson, G.P. and Paul, E.A. (2000) Spatial Heterogeneity of Soil Respiration and Related Properties at the Plant Scale. Plant and Soil, 222, 203-214. http://dx.doi.org/10.1023/A:1004757405147

[26] Kosugi, Y., Mitani, T., Ltoh, M., Noguchi, S., Tani, M., Matsuo, N., et al. (2007) Spatial and Temporal Variation in Soil Respiration in a Southeast Asian Tropical Rainforest. Agricultural and Forest Meteorology, 147, 35-47. http://dx.doi.org/10.1016/j.agrformet.2007.06.005

[27] Robertson, G.P. and Freckman, D.W. (1995) The Spatial Distribution of Nematode Trophic Groups across a Cultivated Ecosystem. Ecology, 76, 1425-1432. http://dx.doi.org/10.2307/1938145

[28] Mori, A. and Takeda, H. (2003) Light-Related Competitive Effects of Overstory Trees on the Understory Conifer Saplings in a Subalpine Forest. Journal of Forest Research, 8, 163-168. http://dx.doi.org/10.1007/s10310-002-0022-y

[29] Robertson, G. (1998) GS+: Geostatistics for the Environmental Sciences. Gamma Design Software, Plainwell. 
[30] Cambardella, C.A., Moorman, T.B., Parkin, T.B., Karlen, L., Novak, J.M., Turco, R.F. and Konopka, A.E. (1994) Field-Scale Variability of Soil Properties in Central Iowa Soils. Soil Science Society of America Journal, 58, 15011511. http://dx.doi.org/10.2136/sssaj1994.03615995005800050033x

[31] Sponseller, R.A. (2007) Precipitation Pulses and Soil $\mathrm{CO}_{2}$ Flux in a Sonoran Desert Ecosystem. Global Change Biology, 13, 426-436. http://dx.doi.org/10.1111/j.1365-2486.2006.01307.x

[32] Zhang, Q., Yang, L., Zhang, W., Luo, H., et al. (2012) Respiration Characteristics of Cotton Soil under Irrigation and Fertilization Measures in Arid Region. Transactions of the Chinese Society of Agricultural Engineering, 28, 77-84.

[33] Bai, J., Wang, J., Chen, X., Luo, G.P., Shi, H., Li, L.H. and Li, J.L. (2015) Seasonal and Inter-Annual Variations in Carbon Fluxes and Evapotranspiration over Cotton Field under Drip Irrigation with Plastic Mulch in an Arid Region of Northwest China. Journal of Arid Land, 7, 272-284. http://dx.doi.org/10.1007/s40333-014-0012-x

[34] Cable, J.M., Ogle, K., Williams, D.G., Weltzin, J.F. and Huxman, T.E. (2008) Soil Texture Drives Responses of Soil Respiration to Precipitation Pulses in the Sonoran Desert: Implications for Climate Change. Ecosystems, 11, 961-979. http://dx.doi.org/10.1007/s10021-008-9172-x

[35] Cable, J.M., Ogle, K., Lucas, R.W., Huxman, T.E., Loik, M.E., Smith, S.D., et al. (2011) The Temperature Responses of Soil Respiration in Deserts: A Seven Desert Synthesis. Biogeochemistry, 103, 71-90. http://dx.doi.org/10.1007/s10533-010-9448-Z

[36] Jassal, R.S., Black, T.A., Novak, M.D., Gaumont-Guay, D. and Nesic, Z. (2008) Effect of Soil Water Stress on Soil Respiration and Its Temperature Sensitivity in an 18-Year-Old Temperate Douglas-Fir Stand. Global Change Biology, 14, 1305-1318. http://dx.doi.org/10.1111/j.1365-2486.2008.01573.x

[37] Joffre, R., Ourcival, J.M., Rambal, S. and Rocheteau, A. (2003) The Key-Role of Topsoil Moisture on $\mathrm{CO}_{2}$ Efflux from a Mediterranean Quercus ilex Forest. Annals of Forest Science, 60, 519-526. http://dx.doi.org/10.1051/forest:2003045

[38] Davidson, E.A., Verchot, L.V., Cattanio, J.H., Ackerman, I.L. and Carvalho, J.E.M. (2000) Effects of Soil Water Content on Soil Respiration in Forests and Cattle Pastures of Eastern Amazonia. Biogeochemistry, 48, 53-69. http://dx.doi.org/10.1023/A:1006204113917

[39] Borken, W., Xu, Y.J., Davidson, E.A. and Beese, A. (2002) Site and Temporal Variation of Soil Respiration in European Beech, Norway Spruce, and Scots pine Forests. Global Change Biology, 8, 1205-1216. http://dx.doi.org/10.1046/j.1365-2486.2002.00547.x

[40] Xu, M. and Qi, Y. (2001) Soil-Surface $\mathrm{CO}_{2}$ Efflux and Its Spatial and Temporal Variations in a Young Ponderosa Pine Plantation in Northern California. Global Change Biology, 7, 667-677. http://dx.doi.org/10.1046/j.1354-1013.2001.00435.x

[41] Naramoto, M. and Wang, Q. (2012) Soil $\mathrm{CO}_{2}$ Flux from Desert Ecosystems in Western China. Journal of Arid Land Studies, 22, 37-40. http://nodaiweb.university.jp/desert/pdf/JALS-B08_37-40.pdf

[42] Epron, D., Nouvellon, Y., Roupsard, O., Mouvondy, W., Mabiala, A., Saint-André, L., et al. (2004) Spatial and Temporal Variations of Soil Respiration in a Eucalyptus Plantation in Congo. Forest Ecology and Management, 202, 149160. http://dx.doi.org/10.1016/j.foreco.2004.07.019

[43] Ngao, J., Epron, D., Delpierre, N., Breda, N., Granier, A. and Longdoz, B. (2012) Spatial Variability of Soil $\mathrm{CO}_{2}$ Efflux Linked to Soil Parameters and Ecosystem Characteristics in a Temperate Beech Forest. Agricultural and Forest Meteorology, 154-155, 136-146. http://dx.doi.org/10.1016/j.agrformet.2011.11.003

[44] Panosso, A.R., Marques, J., Pereira, G.T. and La Scala, N. (2009) Spatial and Temporal Variability of Soil $\mathrm{CO}_{2}$ Emis- $^{-}$ sion in a Sugarcane Area under Green and Slash-and-Burn Managements. Soil \& Tillage Research, 105, 275-282. http://dx.doi.org/10.1016/j.still.2009.09.008

[45] Wang, Y.G., Zhu, H. and Li, Y. (2013) Spatial Heterogeneity of Soil Moisture, Microbial Biomass Carbon and Soil Respiration at Stand Scale of an Arid Scrubland. Environmental Earth Sciences, 70, 3217-3224. http://dx.doi.org/10.1007/s12665-013-2386-Z

[46] Adachi, M., Bekku, Y.S., Rashidah, W., Okuda, T. and Koizumi, H. (2006) Differences in Soil Respiration between Different Tropical Ecosystems. Applied Soil Ecology, 34, 258-265. http://dx.doi.org/10.1007/s12665-013-2386-Z

[47] Adachi, M., Bekku, Y.S., Konuma, A., Kadir, W.R., Okuda, T. and Koizumi, H. (2005) Required Sample Size for Estimating Soil Respiration Rates in Large Areas of Two Tropical Forests and of Two Types of Plantation in Malaysia. Forest Ecology and Management, 210, 455-459. http://dx.doi.org/10.1016/j.foreco.2005.02.011

[48] Rayment, M.B. and Jarvis, P.G. (2000) Temporal and Spatial Variation of Soil $\mathrm{CO}_{2}$ Efflux in a Canadian Boreal Forest. Soil Biology \& Biochemistry, 32, 35-45. http://dx.doi.org/10.1016/S0038-0717(99)00110-8

[49] Rochette, P., Desjardins, R.L. and Pattey, E. (1991) Spatial and Temporal Variability of Soil Respiration in Agricultural Fields. Canadian Journal of Soil Science, 71, 189-196. http://dx.doi.org/10.4141/cjss91-018 
[50] Barba, J., Yuste, J.C., Martinez-Vilalta, J. and Lloret, F. (2013) Drought-Induced Tree Species Replacement Is Reflected in the Spatial Variability of Soil Respiration in a Mixed Mediterranean Forest. Forest Ecology and Management, 306, 79-87. http://dx.doi.org/10.1016/j.foreco.2013.06.025

[51] Ohashi, M. and Gyokusen, K. (2007) Temporal Change in Spatial Variability of Soil Respiration on a Slope of Japanese Cedar (Cryptomeria japonica D. Don) Forest. Soil Biology \& Biochemistry, 39, 1130-1138. http://dx.doi.org/10.1016/j.soilbio.2006.12.021

[52] Konda, R., Ohta, S., Ishizuka, S., Arai, S., Ansori, S., Tanaka, N. and Hardjono, A. (2008) Spatial Structures of $\mathrm{N}_{2} \mathrm{O}$, $\mathrm{CO}_{2}$, and $\mathrm{CH}_{4}$ Fluxes from Acacia mangium Plantation Soils during a Relatively Dry Season in Indonesia. Soil Biology \& Biochemistry, 40, 3021-3030. http://dx.doi.org/10.1016/j.soilbio.2008.08.022 